\title{
“THE CHILL TENT”- AN ORIGINAL ROMANIAN INITIATIVE ON ALCOHOL HARM REDUCTION IN RECREATIONAL SETTINGS
}

\author{
Hriscu Eugen*, Roman Viorel*, Crăciun Oana*
}

*NGO ALIAT pentru Sănătate Mintală, Bucharest, Romania INTRODUCTION:

With 12.6 liters of pure alcohol consumed per capita every year, currently Romania ranks $8^{\text {th }}$ in the WHO Economic region and $9^{\text {th }}$ in the world regarding alcohol consumption (1). However, Romanian men were found to drink the most in the world (8.2 drinks per day), according to a recent meta-analysis (2). With alcohol being responsible for almost $10 \%$ of deaths and burden of illness in the European WHO region (1) and considering that Romania has implemented no country-wide measures to tackle the phenomenon of alcohol abuse and dependence, there is clearly a need for public health interventions on alcohol abuse. With specialized treatment being very scarce and expensive to implement, we looked at harm reduction (HR) strategies. There is a large body of data showing effectiveness of harm reduction strategies in young people, especially in college students (3), but less so with adult populations.

\section{AIMS:}

We are describing a hybrid alcohol intervention that combines $\mathrm{HR}$ strategies with early detection of alcohol problems and brief interventions, according to the WHO model (4). Doing so, we aimed to develop an effective, low threshold, low cost program, easily accessible to different populations, hence its delivery in a recreational setting.

\section{METHODOLOGY:}

Since 2015, a team of around 15 mental health specialists and trained volunteers are deployed for 4 days, three times a year, during the high tourist season in the seaside resort of Vama Veche, Romania. The beneficiaries are self-recruited or attracted through distribution of informational leaflets.

All guests at the Chill Tent ("Cortul de Chill") receive free water, tea or coffee and they are invited to spend some time at the tent, to allow the alcohol effects to wear off. The atmosphere is relaxed, with music in the background and places to sit comfortably.

AUDIT questionnaires (4) are administered, followed by brief interventions with those who score positive. They may also receive leaflets with information on alcohol and health risks, free condoms or sunscreen cream.

The time spent at the tent is also an opportunity for guests to interact with trained psychotherapists and other mental health specialists in real short-term psychotherapeutic encounters. For most people, this is their first taste of what psychotherapy might be like.

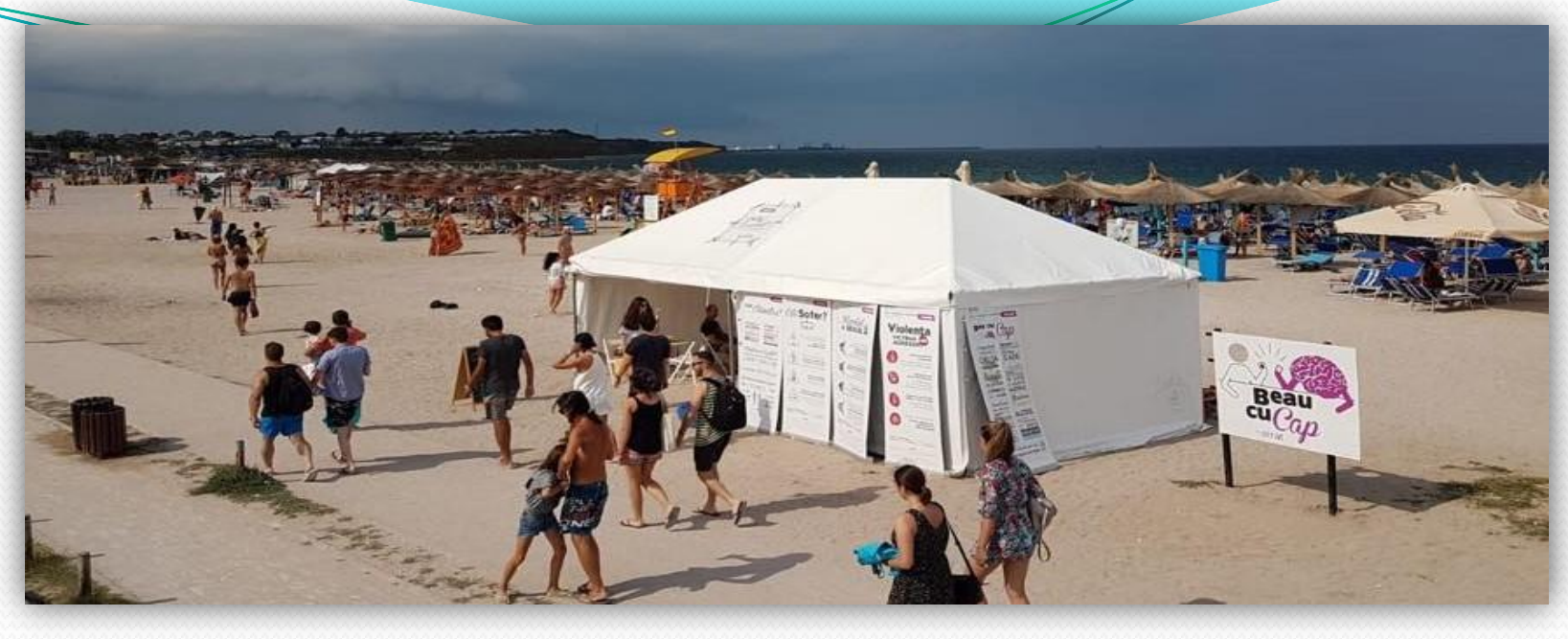

\section{RESULTS:}

In 5 years, more than 25000 people were exposed to alcohol educational messages. 2750 completed the AUDIT and almost half of them were found to be drinking above risk and harmful levels. Other interventions such as general psychological interventions and psycho-education, as well as small medical interventions in emergency cases could not be assessed in terms of long term impact.
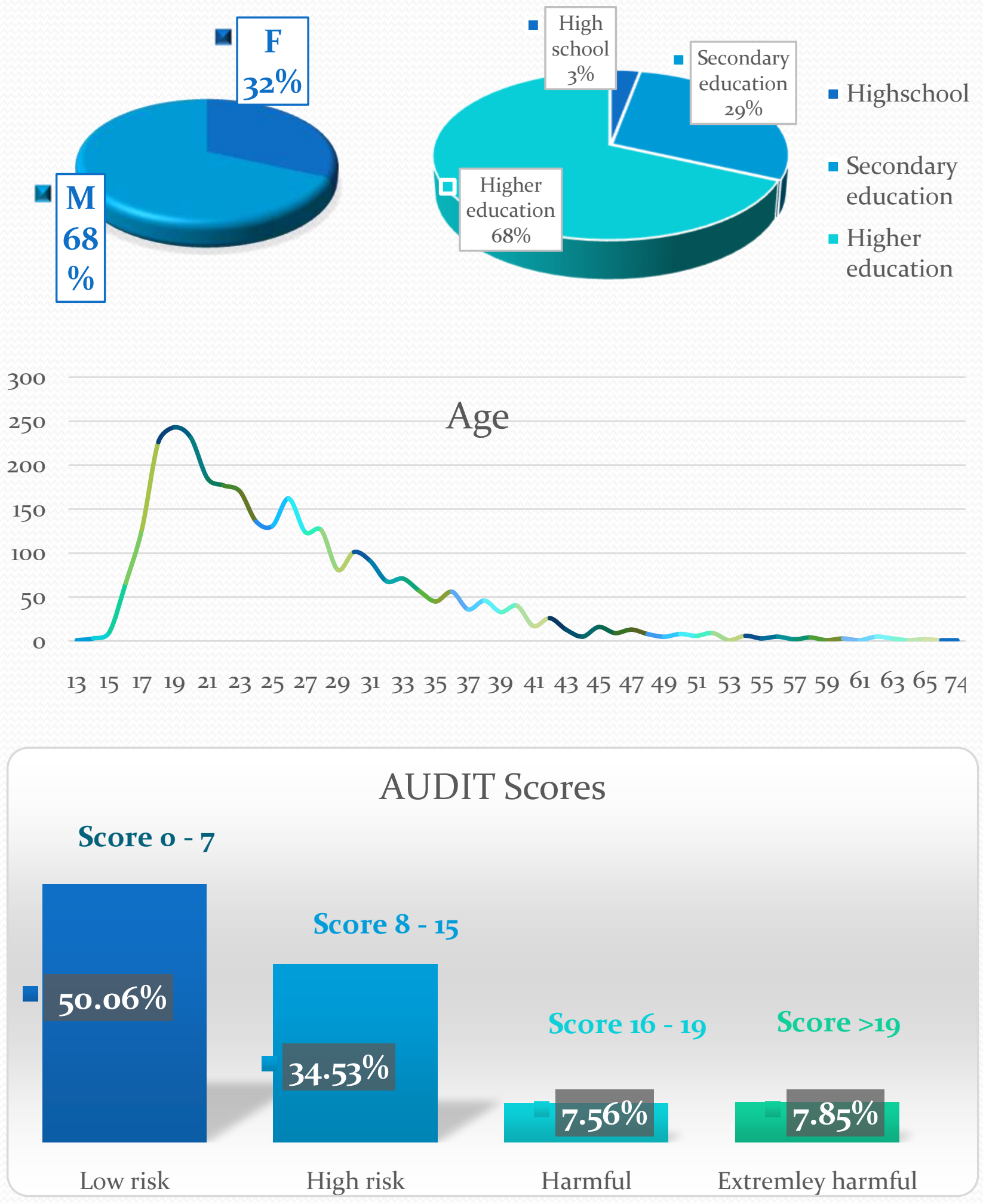

\section{CONCLUSIONS:}

The interventions implemented in the Chill Tent project proved to be well received by the public and an excellent screening tool for at-risk drinkers, with almost half of the responders testing positive on the AUDIT. Also, it managed to attract a significant number of women, who are less represented in traditional alcohol prevention/treatment settings (5). Moreover, the experience gathered so far might prove useful in designing other low-threshold mental health (e.g. depression) interventions for people at risk.

1. WHO, Global status report on alcohol and health, 2018, World Health Organization, Geneva; 2018

2. GBD 2016 Alcohol Collaborators. Alcohol use and burden for 195 countries and territories, 1990-2016: a systematic analysis for the global burden of disease study 2016. Lancet. 2018;392:1015-35

3. Neighbors C, Larimer M. E, Lostutter T. W, Woods B. A. Harm reduction and individually focused alcohol prevention. The International Journal on Drug Policy. 2006;17(4):304-309

4. Babor T.F., Higgins-Biddle J.C., Brief intervention for hazardous and harmful drinking : a manual for use in primary care. WHO, 2001 